University of Nebraska - Lincoln

DigitalCommons@University of Nebraska - Lincoln

Agronomy \& Horticulture - Faculty Publications

Agronomy and Horticulture Department

9-16-1949

\title{
A Filter Paper "Chromatopile"
}

Herschel Mitchell

Kerckhoff Laboratories of Biology, California Institute of Technology, Pasadena

Francis A. Haskins

University of Nebraska-Lincoln, fhaskins@neb.rr.com

Follow this and additional works at: https://digitalcommons.unl.edu/agronomyfacpub

Part of the Plant Sciences Commons

Mitchell, Herschel and Haskins, Francis A., "A Filter Paper "Chromatopile"'" (1949). Agronomy \& Horticulture -- Faculty Publications. 157.

https://digitalcommons.unl.edu/agronomyfacpub/157

This Article is brought to you for free and open access by the Agronomy and Horticulture Department at DigitalCommons@University of Nebraska - Lincoln. It has been accepted for inclusion in Agronomy \& Horticulture -Faculty Publications by an authorized administrator of DigitalCommons@University of Nebraska - Lincoln. 
A diagrammatic sketch of a cross section of the column is shown in Fig. 1. It consists essentially of three parts:

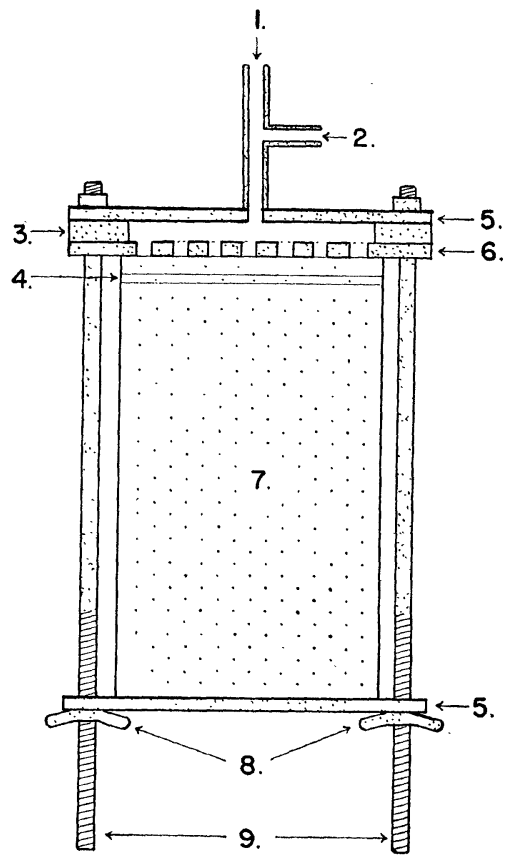

Fra. 1. Diagram of the filter paper pile column. 1. Connection for a rubber tube for filling the siphon. 2. Connection for the siphon tube. 3. Rubber gasket. 4. Filter paper disks containing the sample. 5. Stainless steel plates. 6 . l'eriorated stainless steel plate. $T$. Filter paper disk pile. 8. Wint nuts. 9. Bolts at four corners of steel plates.

the pile of filter paper itself (No. 7 in Fig. 1), a clamp for packing the paper tightly, and the solvent distributor at the top of the pile. The metal parts are constructed from stainless steel. The solvent distributor is connected by a siphon of rubber tubing to a 2-1 flask containing about 11 of solvent mixture. The flask is adjusted so that the level of the solvent is eren with the top of the paper pile. In operation the column is placed upright on the ends of the clamp bolts in a $9 \mathrm{in.} \times 12 \mathrm{in.} \mathrm{battery}$ jar containing about $200 \mathrm{ml}$ of solvent mixture. The jar is covered, with a hole left for the siphon tube.

The results of a trial run on known compounds will serve to illustrate the utifity of the apparatus. Fifty $\mathrm{mg}$ each of adenine, tryptophane, phenylalanine, $p$-aminocinnamic acid, and anthranilic acid was dissolved in $20 \mathrm{ml}$ of $0.1 \mathrm{~N} \mathrm{HCl}$ and the solution was placed in the lid of a 100-mm Petri dish. Disks of 9-cm Whatman No. 1 filter paper were immersed in the solution, allowed to drain, and hung up to dry in air at room temperature. Twenty-five sheets were required to take up the solution and rinsings. To prepare for packing the column, the bottom plate of the clamp was removed and the clamp placed in an inverted position with the solvent distributor down. Forty filter paper disks $(9 \mathrm{~cm}$ diam) were then placed carefully in the center of the perforated plate, followed by the 25 dried sheets containing the sample. The remainder of the column was made up of a pile of

This work was supported by funds from the Rockefeller Foundation and from the Atomic Energy Commission administered through contract with the Office of Naval Research, U. S. Navy, Contract NGonr-244 Task Order V. 
8 packages of filter paper $(9 \mathrm{~cm}$, Whatman No. 1 ; total, 865 sheets). After careful alignment of the paper disks, the bottom plate of the clamp was placed on the pile and the wing nuts tightened as much as possible without mechanical aid. The column was then placed in the battery jar with the solvent distributor up. The distributor was then filled with the solvent mixture ( 3 parts $n$-butanol; 1 part tert-butanol and 1 part of $0.1 \mathrm{~N} \mathrm{HCl}$ ) with a pipette, and the siphon from the solvent container was connected and filled. After $28 \mathrm{hr}$ the solvent front had descended $13.2 \mathrm{~cm}$. The column was then removed from the jar and the pile taken out in sections. After the approximate locations of the five compounds had been determined by qualitative means, disks were taken 6,10 , or 20 at a time and extracted with hot $0.1 \mathrm{~N} \mathrm{HCl}$ for adenine, tryptophane, and phenylalanine and hot $0.1 \mathrm{~N}$ $\mathrm{NH}_{4} \mathrm{OH}$ for the remaining two compounds. Adenine, tryptophane, and $p$-aminocinnamic acid concentrations in the extracts were determined with the Beckman Spectrophotometer. Phenylalanine was determined colorimetrically with ninhydrin, and anthranilic acid fluorometrically with a Coleman Photofluorometer. The total recoveries of compounds from the column sections analyzed were: adenine, $41 \mathrm{mg}$; tryptophane, $46 \mathrm{mg}$; phenylalanine, $46 \mathrm{mg}$;

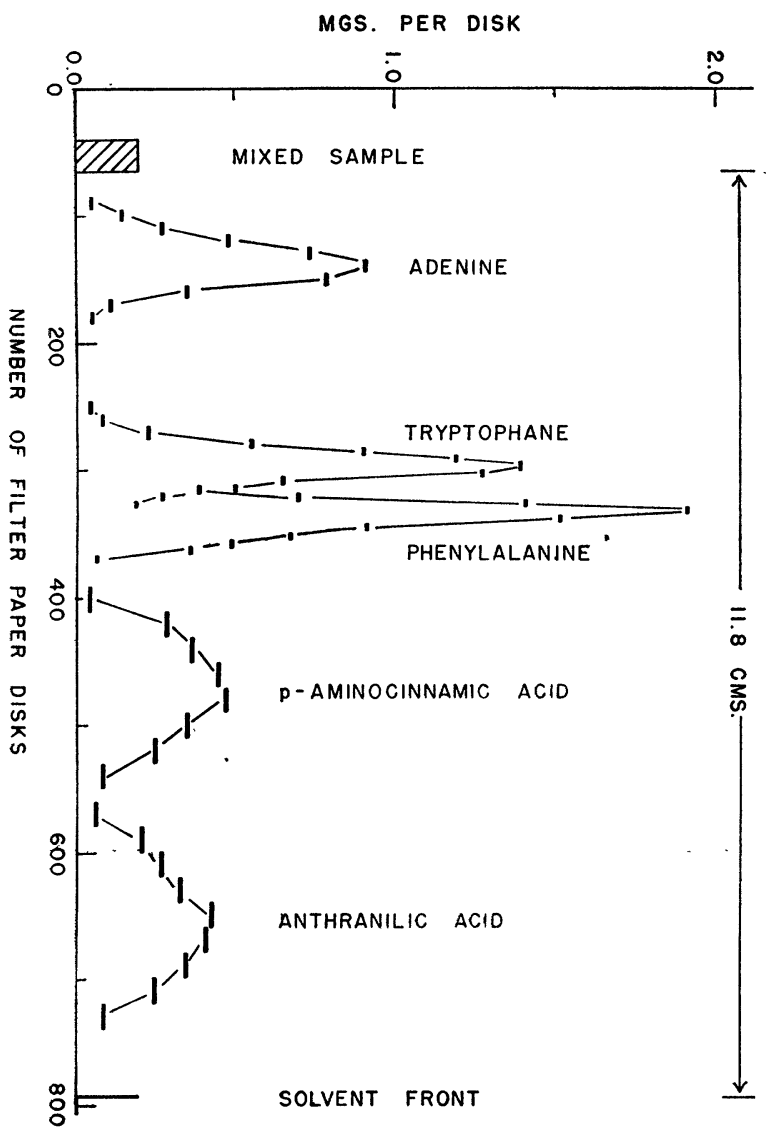

Fig. 2. Results of an experiment showing the separation of compounds of a known mixture. The length of the horjzontal bars used for experimental points inclicates the number of paper disks extracted for each analytical sample. $p$-aminocinnamic acid, $44 \mathrm{mg}$; and anthranilic acid, 46 mg. Thus, without considering losses in sheets removed for qualitative tests, $223 \mathrm{mg}$ was recovered from the original $250 \mathrm{mg}$ in the mixed sample. The distribution of the compounds on the column is shown in Fig. 2. As noted in the figure, the solvent traveled from the last sheet of the mixed sample through 730 filter paper disks or a distance of $11.8 \mathrm{~cm}$. In the case of the sharpest peak (phenylalanine) more than $95 \%$ of the compound recovered was found in 36 filter paper disks representing a thickness of a little less than $6 \mathrm{~mm}$. With such a degree of resolution it is clear that the solvent front movement is remarkably uniform in this type of column. Color tests made directly on sample disks showed a slightly more rapid movement of solvent at the edges, but the difference in rate is apparently negligible.

The simplicity and ease of operation of the filter paper pile column provides a praeticable method for isolations without requiring complicated equipment. One feature which is most desirable is the ease with which a sample can be removed and incorporated into a new pile. Thus, a section of disks containing a desired compound can be taken out and placed in a new pile for use with a different solvent mixture.

\section{References}

1. Consden, R. Gordon, A. H., and Martin, A. J. P. Biochem. J., 1947, 41, 590 .

2. Dent, C. E. Biochem. J., 1947, 41, 240.

3. Martin, A. J. P. and Synge, R. L. M. Biochem. J., 1941, $35,1358$.

4. Strin, W. H. and Moore, S. J. biol. Chem., 1948, 176, 337.

5. Vischer, E. and Chargaff, E. J. biol. Chem., 1948, 176 , 703.

6. Williams. R. J. and Kirby, H. Science, 1948, 107, 481. 